\title{
Correction to: Patients with an Achilles tendon re-rupture have long-term functional deficits and worse patient-reported outcome than primary ruptures
}

\author{
Olof Westin ${ }^{1,2} \cdot$ Katarina Nilsson Helander $^{1,2,3} \cdot$ Karin Grävare Silbernagel $^{1,5} \cdot$ Kristian Samuelsson $^{1,2}$. \\ Annelie Brorsson ${ }^{1,4} \cdot$ Jón Karlsson ${ }^{1,2}$
}

Published online: 17 May 2018

(c) European Society of Sports Traumatology, Knee Surgery, Arthroscopy (ESSKA) 2018

\section{Correction to: \\ Knee Surgery, Sports Traumatology, Arthroscopy \\ https://doi.org/10.1007/s00167-018-4952-0}

Unfortunately, the title of the article contained a mistake in the online publication of the article.

The correct title should be read as follows:

Patients with an Achilles tendon re-rupture have longterm functional deficits and worse patient-reported outcome than primary ruptures.

The original article can be found online at https://doi.org/10.1007/ s00167-018-4952-0.

Olof Westin

olof.westin@gmail.com

1 Department of Orthopaedics, Institute of Clinical Sciences,

The Sahlgrenska Academy, University of Gothenburg,

Gothenburg, Sweden

2 Department of Orthopaedics, Sahlgrenska University Hospital, Mölndal, Sweden

3 Hallands Sjukhus, Kungsbacka, Sweden

4 IFK Kliniken Rehab, Gothenburg, Sweden

5 Department of Physical Therapy, University of Delaware, Newark, DE, USA 